\title{
Effect of Suntyadi Churna As Nutraceutical Candy In Menstrual Dysfunction (Oligomenorrhoea) Among Young Adult Females
}

\author{
Divya $R^{1}$, V. K. Sunitha', Sajitha Bhadran ${ }^{3}$ \\ ${ }^{1}$ Asst.Professior, Dept.of PG Sudies in Swaasthavritta , JSS Ayurveda Medical College, Mysore-570028 \\ ${ }^{2}$ Professor, Dept. of Swasthavritta, Govt . Ayurveda College, Thiruvanathapuram \\ ${ }^{3}$ Associate Professor, Dept. of Swasthavritta, Govt . Ayurveda College, Thiruvanathapuram
}

\begin{abstract}
Oligomenorrhoea is a medical term which generally refers to irregular or infrequent menstrual periods with intervals of more than 35 days. However the duration may vary and the affected women typically menstruate between $4 \& 9$ times per year. Prevalence of PCOS in Indian adolescents ranges from $2.2 \%-26 \%$; out of this $0.22 \%$ had Oligomenorrhoea/ amenorrhea \& $6.30 \%$ had Oligomenorrhoea with $\operatorname{PCOS}^{1}$. Ayurveda has a pivotal role in the treatment and prevention of Oligomenorrhoea. Most of them are much cheaper when compared to the contemporary drugs available in the market. The Suntyadi churna ${ }^{2}$ told in the classics in the ratio of sunti-100gm, gudam-200gm and krishnatilam-400gm was prepared and given in candy form which prevents menstrual disorders, PCOS and also aims at future female health. The primary objective of the study was to evaluate the effect of Suntyadi churna as nutraceutical candy in Oligomenorrhoea. It was an interventional pre-post study with a sample size of 30 cases within age group 18-25 years was selected from the Out patient division of Swasthavritta Department, Govt. Ayurveda College and Hospital, Thiruvananthapuram. A detailed history was taken according to the case proforma. Known cases of structural uterine abnormalities and chronic systemic illnesses on medication, secondary dysmenorrhoea, known psychiatric cases and married women were excluded.

After collecting the baseline data of subjects, the prepared candy was given in small packets in the dose of $12 \mathrm{gm}$ before food twice daily along with luke warm water as anupana for 3 months excluding days of menstruation (7 days) and assessment was done. Statistical analysis was done by using Paired t test and the preparation was found to be effective in Oligomenorrhoea.
\end{abstract}

Key words : Suntyadi churna,Oligomenorrhoea, Nutraceuticals, PCOS, Anupana

\section{Introduction}

Women constitute approximately $50 \%$ of the population in almost all countries of the world. Distinct changes in their built and behavior is obviously observed starting from the intra-uterine life, childhood, adolescence and till death. The female reproductive system is more complex than its male counterpart; therefore it is subjected to more frequent disturbances and hence deserves additional personal care. 3 Menstruation, the physiological phenomenon on being vitiated turns into a recurrent agonizing ordeal of womanhood. Adolescence can be regarded as a milestone towards maturity. The advent of menstruation and discomforts associated with the menstrual irregularities convert this natural physiological process into a nightmare and poses hindrance in the personality development of the teenager ${ }^{4}$. 


\section{Divya R, International Journal of Ayurvedic \& Herbal Medicine 8(4) July.-August. 2018 (3300-3306)}

Around $80-90 \%$ of teenage girls report menstrual problems and $40-50 \%$ complain it as severe. The physical and psychological distress experienced by teenager during menstrual irregularities is the outcome of both bodily dysfunction and emotional turmoil.

Oligomenorrhoea is a medical term which generally refers to irregular or infrequent menstrual periods with intervals of more than 35 days, however the duration may vary and the affected woman typically menstruates between $4 \& 9$ times per year. Oligomenorrhoea can result in infertility also. Women with polycystic ovarian syndrome (PCOS) are also likely to suffer from Oligomenorrhoea. It can become amenorrhea if menstruation stops for 6 months or more. Eating disorders can also result in Oligomenorrhoea/ amenorrhea. Most common cause of anovulatory infertility in women is $\operatorname{PCOS}^{5}$.

The underlying emotional and hormonal imbalance associated with menstrual abnormalities is rectified by the regular use of the nutraceutical preparation. The high incidence of the ailment and elevated degree of distress it creates in youngsters and also the limited success of Modern medicines with absence of side effects has been potential contributory factor in taking up this study ${ }^{6}$.

There are many formulations mentioned in Ayurveda for correcting menstrual derailment. In Ashtanga Hridaya, there is description of Suntyadi Churna in Gulma chikitsa comprising of sunti, tilam and gudam. The raktha sodhaka and arthava janana property of the drugs is well known. Sunti acts as a circulatory stimulant and also a potent inhibitor of prostaglandins. Gudam is a very rich source of iron and has lots of anti-oxidants. So here in this study, a humble attempt is made to give Suntyadi churna in the form of nutraceutical candy with luke -warm water as anupana.

Nutraceutical can be defined as "A food or part of food or nutrient that provides extra health benefits including the prevention and treatment of a disease ${ }^{7}$." In present living conditions role of nutraceuticals remain unquestioned. So Suntyadi churna which is of high nutritive value is given in the form of nutraceutical candy for convenient administration. Thereby we can provide a healthy dietary supplement for the youngsters without side effects. With this back ground the present study the study has been undertaken to evaluate the effect of suntyadi churna as a nuetraceutical candy in menstrual dysfunction among yuong adult females .

\section{Objective of the study}

To evaluate the effect of Suntyadi Churna as Nutraceutical Candy in Oligomenorrhoea

\section{MATERIALS AND METHODS}

The present study was carried subjects suffering from the symptoms of Oligomenorrhoea selected from Out Patient Division of Swasthavritta, Panchakarma Hospital, Govt.Ayurveda College, Thiruvananthapuram.

\section{Population:}

30 adult females aged 18-25 years who are having irregular menstrual cycles were selected as per the inclusion criteria for the study from the Out Patient Division of Swasthavritta department.

\section{Inclusion criteria:}

Patients having symptoms of Oligomenorrhoea coming under 18-25 age group

\section{Exclusion criteria:}

1. Known cases of structural uterine abnormalities and chronic systemic illnesses on medication.

2. Secondary dysmenorrhea

3. Known psychiatric diseases.

Study design: An Interventional - pre and post study. A written informed consent in local language was obtained from the subjects before the study. The whole procedure was explained to them before the start of the study as a part of ethical consideration. 


\section{Assessment}

Bleeding duration and cycle interval were the outcome variables of the study

Assessment of outcome variables was done before study, during the study period (after 60 days) and after the study (after 90 days) by using Paired t' test.

Drug Preparation ${ }^{8}$

Ingredients were taken in the ratio Sunti(dry ginger )- 1, Gudam(jaggary)-2 and Krishnatilam(black sesame seeds)-4 respectively. Krishnatilam(400g)and sunti(100g) were washed, cleaned and separately kept in sunlight for drying. Dried krishnatilam was fried, crushed and sunti was crushed, powdered and strained. Both churnas were mixed and stirred well. Gudam(200g) was melted to get tantupakam and filtered. The mixture of churnas were added to the gudam and stirred thoroughly to get the churna equally and uniformly mixed and candy of $12 \mathrm{gm}$ size were prepared manually. The prepared candy after cooling was kept in an air tight container and was dispensed in small air tight packets containing twenty candies for ten days during first visit. It was administered twice daily before food with boiled and cooled water as anupana for three months excluding menstruation days

\section{Analysis}

The collected data were arranged in a master sheet and it was computed. Frequencies and percentages were used for summarizing the collected data. The mean scores of the parameters before and after treatment were analyzed and interpreted by using Paired t' test.

\section{Observations and Results}

Major characteristics in our study were sample size was adequate and baseline data was also suitable. It was filed that majority of the subjects (80\%) were accustomed to junk foods and $20 \%$ followed traditional food. Among the 30 cases $46.66 \%$ experienced mandagni, 36.66\% had samagni, $13.33 \%$ had vishamagni and $3.33 \%$ experienced tikshnagni. It is observed that all the samples (100\%) had irregular menstrual pattern. It is also observed that majority $(43.33 \%)$ experienced 6 months-2 years menstrual irregularity, remaining since 4-6 years(30\%), 2-4 years and 6-8 years(13.33\%). Regarding bleeding duration 3-4 days bleeding duration $(36.66 \%)>7$ days duration (30\%) 5-7 days duration (23.33\%) and $10 \%$ were reported as $<3$ days duration was observed

\section{Response to treatment was observed as follows}

As per the table 1, it is observed that before the treatment mean of the bleeding duration was 6.63 and during treatment mean was observed as 8.23 and after treatment the mean was observed as 5.83 .The mean difference after pairing was -1.60 , with $\mathrm{SD} 3.092, \mathrm{t}$ value was 2.835 with $\mathrm{p}$ value 0.0083 , which is considered as very significant. After comparing the values during treatment and after treatment, it is observed that the mean difference was 2.40 with SD $1.354, \mathrm{t}$ value 9.705 with $\mathrm{p}$ value $<0.0001$ which is considered as highly significant. After comparing the values of before treatment and after treatment, it is observed that the mean difference was 0.80 with SD 3.547, $\mathrm{t}$ value 1.235 with $\mathrm{p}$ value 0.2266 , which is considered as less significant.

As per the table.2, it is observed that the mean interval before treatment was 59.4, during treatment was 46.67 and after treatment it was 37.97. After comparing the values of before treatment and during treatment the mean difference was observed as 12.733 with $t$ value 4.851 and $p$ value $<0.0001$ which is considered as highly significant. The mean difference after comparing the values of during treatment and after treatment was 8.70 with $t$ value 2.505 and significant at the level of $(\mathrm{p}<0.0181)$. Mean difference after comparing the values of before treatment and after treatment was 21.433 with t value 5.268 and $(p<0.0001)$, considered as highly significant.As per the table 3 , it is observed that the mean interval of hemoglobin level before 


\section{Divya R , International Journal of Ayurvedic \& Herbal Medicine 8(4) July.-August. 2018 (3300-3306)}

treatment was 12.167 and it changed to 12.637 after the treatment. After pairing of the values of before treatment and after treatments, value was obtained as 6.078 with $(\mathrm{p}<0.0001)$ which is considered as highly significant

Table no 1. Assessment of effectiveness of treatment on bleeding duration

\begin{tabular}{|c|c|c|c|c|c|c|c|c|}
\hline & \multirow[t]{2}{*}{$\mathrm{N}$} & \multicolumn{2}{|c|}{ Duration } & \multirow[t]{2}{*}{$\begin{array}{c}\text { Paired } \\
\text { comparison }\end{array}$} & \multicolumn{2}{|c|}{$\begin{array}{c}\text { Paired } \\
\text { difference }\end{array}$} & \multicolumn{2}{|c|}{ Paired $t$ test } \\
\hline & & $\mathrm{M}$ & SD & & M & SD & t value & $\mathrm{p}$ value \\
\hline BT & 30 & 6.63 & 3.943 & BT-DT & -1.60 & 3.092 & 2.835 & 0.0083 \\
\hline DT & 30 & 8.23 & 1.675 & DT -AT & 2.40 & 1.354 & 9.705 & $<0.0001$ \\
\hline AT & 30 & 5.83 & 0.913 & BT-AT & 0.80 & 3.547 & 1.235 & 0.2266 \\
\hline
\end{tabular}

Table no 2. Assessment of effectiveness of treatment on interval of cycles

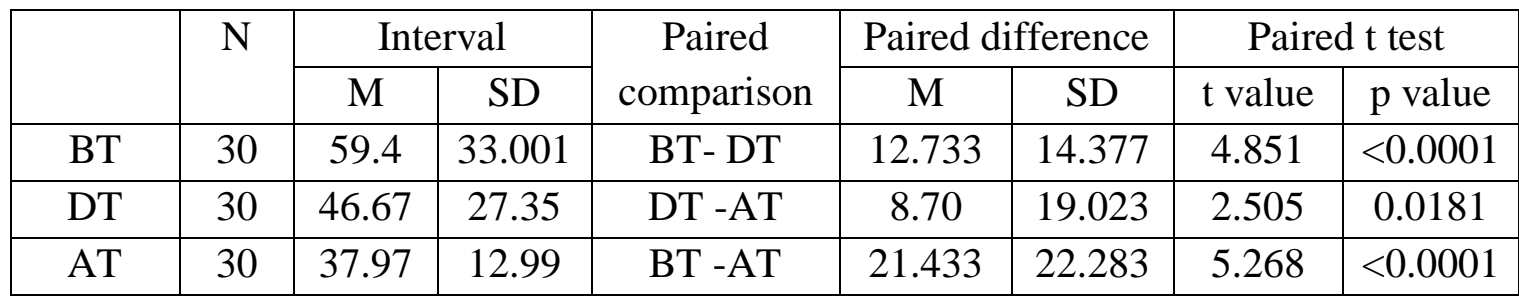

Table no 3. Assessment of effectiveness of treatment on $\mathrm{Hb}$ concentration

\begin{tabular}{|c|c|c|c|c|c|c|c|c|}
\hline & \multirow[t]{2}{*}{$\mathrm{N}$} & \multicolumn{2}{|c|}{ Interval } & \multirow[t]{2}{*}{$\begin{array}{c}\text { Paired } \\
\text { comparison }\end{array}$} & \multicolumn{2}{|c|}{$\begin{array}{c}\text { Paired } \\
\text { difference }\end{array}$} & \multicolumn{2}{|c|}{ Paired $t$ test } \\
\hline & & $\mathrm{M}$ & SD & & $\mathrm{M}$ & SD & t value & $p$ value \\
\hline BT & 30 & 12.167 & 0.6697 & $\mathrm{BT}-\mathrm{AT}$ & - & 0.4236 & 6.078 & $<0.0001$ \\
\hline $\mathrm{AT}$ & 30 & 12.637 & 0.4375 & & 0.4700 & & & \\
\hline
\end{tabular}

\section{Discussion}

Faulty food habits and sedentary life style are more prevalent in urban dwellers and they are forced to live in a high cost environment, which can be a risk factor for menstrual dysfunctions. Therefore a comparatively low cost nutritional supplementation with multidimensional action is of high significance.

Habitual intake of junk foods supply excess energy, protein and fat but provide inadequate supplement of micronutrients like iron and $\beta$ carotene. Pre menstrual symptoms were high in girls consuming junk foods and non-vegetarian diet. Consumption of junk foods, sugar rich foods and irregular eating schedule causes a fluctuation in the glucose levels and hormonal imbalance leading to the deposition of fat particularly in hips and abdominal region which inturn leads to PCOS.

The provoking factors of the disease is attained by dhathu soshana and thereby arthava kshaya by the intake of excessive pungent, salt and sour taste.

The major ingredient present in most of the confectionary foods consumed by the adolescent age group presently is Maida i.e.; refined flour, which is having bad effects on the body. Foods that are made from Maida have a high glycemic index eg; noodles, pasta, white bread, cream biscuits, pastry, pizza, burger, butter bun etc, will digest quickly and release sugar into the blood stream fastly, causes a sharp insulin response which, over a period of time, with prolonged consumption of processed and refined foods leads to obesity, insulin resistance and eventually type 2 diabetes which also results in menstrual irregularity. When 


\section{Divya R , International Journal of Ayurvedic \& Herbal Medicine 8(4) July.-August. 2018 (3300-3306)}

foods containing maida are fried, eg; samosa, the body gets an overdose of fat and refined carbohydrates which disrupts metabolism leading to inflammation, heart disease and even cancer.

PCOS associated with Oligomenorrhoea had an increased risk of sleep disorders. Lack of proper sleep affects proper hormonal function which in turn results in lack of ovulation noticeable in Oligomenorrhoea or Amenorrhea associated with PCOS which finally leads to obesity.

Increased intake of tea and coffee affect the melatonin synthesis which result in disturbed sleep which in turn affects hormone metabolism and leads to PCOS associated with Oligomenorrhoea.

Stress/anxiety/irritability has direct relationship with menstrual irregularity. Menstruation temporarily stops when stress level rises; the condition is known as secondary amenorrhea. Stress factor suppresses the normal functioning of Hypothalamus, which is controlling the Pituitary gland, thyroid gland, adrenals and ovaries which leads to estrogen malfunction which in turn results in total ovarian dysfunction.

Frequent intake of akala ahara results in the lack of rasa dhatu formation which in turn reduces the subsequent dhatus. So intake of food according to rules and regulations mentioned in Ayurveda is necessary for the proper functioning of all the dhatus.

Ayurveda recommends number of drugs to help and maintain the health of female reproductive system thereby promoting their health.

Krichrarthava or Nashtarthava or Oligomenorrhoea involves raktha kshaya as the major symptom. Hence the treatment should be of raktha vardhaka type. Since pitha and raktha are having asraya asrayi bandha, increase of any one may increase the other. Therefore the drugs chosen for the study obviously has the property of increasing pitha and raktha.

The properties of pitha are as follows-

\section{"Pitham sasneha tikshnoshnam laghu visram saram dravam"}

Krishnatila (black sesamum), Sunti (dried ginger) and Gudam (jaggery) are the ingredients of the preparation. Krishnatila is having madhura, kashaya and tiktha rasa. Kashaya and tiktha rasa increases pitha. It is having guru and snigdha guna. Pitha dosha is also having slight snigdha guna so that the snigdha guna of krishnatila is suitable to increase pitha. Krishna tila is having ushna virya, which is evidently an important property in increasing pitha, as pitha is naturally ushna guna. It is having an inherent property of arthava janana i.e. generation of menstrual blood. Due to yogavahi property, krishnatilam enhances the medicinal qualities of the preparation and also helps to reach deeper tissues. Moreover it is having soola prasamana property, which is useful in painful and scanty menstruation. In vipaka it is katu, which also helps in increasing the pitha. Along with these gunas krishnatila is having medhya, keshya, varnya, vatahara and agni vardhaka gunas. They will give added advantage to the patients. Thus an overall improvement of health is achieved.

Sunti is having katu rasa and ushna virya which helps in increase of pitha and raktha. Its laghu snigdha and teekshna gunas also helps in increasing pitha and thereby raktha. In general, sunti is kaphavata samaka that means it aids in pitha vardhana. Sunti is having vatanulomana, sulaprasamana and raktha sodhaka property. Analgesic, circulatory stimulent and blood purificatory effects of sunti add to the positive outcomes of the study. Along with that sunti is rochana, deepana, and vedanasthapana. The pro-digestive properties of sunti aids in proper digestion and the formation of rasa becomes normal and clearer preventing formation of ama (impure, undigested food or toxin generation). Proper formation of rasa dhathu aids in genesis of next dhathu that is raktha.

Even though Guda (ikshu vikara) is pithasamaka in nature, the choice of guda in the study is validated by the fact that no dosha should be allowed to aggravate without control. So there should be some counter balance for the action of sunti and krishna tila. Guda is also having a raktha prasadaka property. It made the preparation palatable and acts as a base to give an effective consistency to the Nutraceutical preparation. 


\section{Divya R, International Journal of Ayurvedic \& Herbal Medicine 8(4) July.-August. 2018 (3300-3306)}

Guda is having moothrala property - helped to remove the accumulated kleda and thereby ama from the body; its brimhana and balya guna helped in the overall improvement of health.

Thus krishnatila and sunti helped in the increase of pitha and thereby increase in raktha. Increased raktha dhathu helps in normal genesis of arthava in time. By three months use of medicine the interval and quantity of menstruation became normal and regular than what was before the study. This is suggestive and affirmative of the correcting properties of these drugs in menstruation. The combined action of the three drugs will help to improve female health without aggravation of any of the doshas beyond control.

Suntyadi churna which is explained in Gulma chikitsa is given in the form of Nutraceutical candy in menstrual dysfunction. The action of the three drugs is correction, genesis and purification. Thus the impaired duration of the menstrual cycles got corrected by the judicial administration of the medicine. By its genesis property, fresh blood is formed in the body; preparation of the body for elimination of impure blood is facilitated. The sodhaka and prasadaka properties of the drugs helped in the purification of blood.

The combination of sunti, gudam and tilam was found to be effective in improving hemoglobin concentration also, as the properties of them are raktha sodhaka, raktha prasadaka and arthavajanana respectively.

Anupana is an agent added to a medicine to increase its potency. A medicine prescribed with proper anupana is more effective than when administered singly, as it helps to bring about the desired effect more quickly. Anupana helps in absorption and assimilation, thus increases the efficacy of the drug.

In the present study luke warm water is prescribed as anupana. In general, anupana is having the properties like tarpanam (tones up the body), preenanam(gives satisfaction), brimhanam (causes plumpiness)etc. Luke warm water helps in digestion by its properties like bhuktham avasadanam (easy downward movement of ingested material), anna sanghatam bhinathi(breaks the hard material of food particles), mardavajananam(makes it soft), kledanam(moistening), sukha parinamam(helps for easy digestion and distribution to all parts of the body). Luke- warm water helped in the formation of raktha dhathu by proper absorption of medicine Also it is kapha vilayanam, quickly relieves trishna, enhances the digestive power, softens and purifies the srotases, does the anulomanam of leena pitha, vatha, sweda, sakrith and mutra. The idea behind the mode of action of nutraceuticals is to provide functional benefits by increasing the supply of natural building blocks in the body which is derived from food sources that provides extra health benefits in addition to the basic nutritional value found in foods.

Thus the decision to prepare the medicines in a nutraceutical form was to provide benefit to the patients with the inherent desirable qualities of medicines and at the same time a palatable preparation which will not create any mental aversion to the medicines.

The outcome variables were bleeding duration and bleeding interval which was measured before treatment, during treatment and after treatment from the study subjects and results were interpreted using 'paired $t$ ' test.

\section{a) Bleeding duration}

Mean bleeding duration before treatment was found to be 6.63. After treatment the mean was observed as 5.83. After the comparison of values of before treatment and during treatment, $t$ value was 2.835 with $p$ value 0.0083 , which is considered as significant. The $t$ value was observed as 9.705 with $(\mathrm{p}<0.0001)$ which is considered as highly significant after comparing values of during treatment and after treatment and after the paired comparison of values of before and after treatment, $t$ value was found to be 1.235 with $p$ value 0.2266 which is less significant.

b) Cycle interval

Before treatment, the mean interval of cycles between two menstrual periods was found to be 59.4. After treatment, it changed to 37.97, which is considered as significant. After paired comparison of values of BT 


\section{Divya R, International Journal of Ayurvedic \& Herbal Medicine 8(4) July.-August. 2018 (3300-3306)}

to DT, $t$ value was observed as 4.851 at $(\mathrm{p}<0.0001)$ which is considered as highly significant. The $t$ value obtained after comparing the values of DT to AT, was 2.505 which is significant at the level of ( $\mathrm{p}<0.0181)$ and after the comparison of values of BT to AT, t value was obtained as 5.268 at $(\mathrm{p}<0.0001)$, considered as highly significant.

\section{Effect on Hb concentration}

The hemoglobin concentration was also noted as the nutraceutical preparation was found to be effective in increasing the $\mathrm{Hb} \%$.

The mean interval of hemoglobin level before treatment was 12.167 and it changed to 12.637 after the treatment. After pairing of the values of before treatment and after treatment, ' $t$ ' value was obtained as 6.078 with $(\mathrm{p}<0.0001)$ which is considered as highly significant.

Thus the study using the drugs Sunti, Krishnatila and Gudam in a nutraceutical form was found to be effective in correcting the intervals of menstruation, quantity of menstrual blood and gave regularity in the cycles. It further throws light into the scope for a wider study involving a larger sample size i.e. an extensive research. Along with this, the same combination of drugs was also found to be effective in improving $\mathrm{Hb}$ level. Hence, it could be useful in treating anemia also.

\section{Conclusion}

The objective of the study is to evaluate the effect of Suntyadi churna as Nutraceutical candy in menstrual dysfunction (Oligomenorrhoea) among young adult females has provided the following conclusions.

The prescribed Nutraceutical preparation is highly effective in the management of menstrual irregularities among adolescent age group.

There was a highly significant reduction in bleeding duration at $\mathrm{p}<0.0001$

There was a highly significant reduction in cycle interval at $\mathrm{p}<0.0001$

There was a highly significant reduction in the interval of bleeding at $p<0.0001$

PCOS associated with Oligomenorrhoea and Dysmenorrhoea has shown significant response after the intervention.

The combination of the drugs (sunti, gudam and tilam) is found to be effective not only in Oligomenorrhoea, but also in increasing the hemoglobin concentration. So the same combination can be given to treat anemia also.

\section{References}

1. Howkins \& Bourne Shaw's text book of Gynaecology, $15^{\text {th }}$ edition by V.G.Padubidri, S.N.Daftary, page no. 283

2. Vagbhata's Ashtanga Hridayam by Prof. K.R. Srikantha Murthy Vol 1, $7^{\text {th }}$ Edition 2010 Chowkhamba Krishnadas Academy Varanasi Ah. Sa.1/11(Arunadutta)

3. Sujith.K.Chaudhari, Concise medical physiology, $5^{\text {th }}$ edition, page no.313,314.

4. www.ncbi.nlm.in

5. Harrison's Principles of Internal Medicine, $17^{\text {th }}$ edition, page no.304

6. https://en.wikipedia.org/wiki/oligomenorrhoea

7. https://en.wikipedia.org/wiki/nutraceuticals

8. Vagbhata's Ashtanga Hridayam by Prof. K.R. Srikantha Murthy Vol 1, $7^{\text {th }}$ Edition 2010 Chowkhamba Krishnadas Academy Varanasi Ah. Sa.1/11(Arunadutta) 